\title{
A prospective study on awareness of postnatal mothers regarding self and newborn care in a tertiary care centre in Mangalore, Karnataka
}

\author{
Pradeep Ganiga, Sourabha S. Shetty*
}

Department of Obstetrics and Gynecology, AJIMS, Mangalore, Karnataka, India

Received: 18 October 2020

Accepted: 03 December 2020

\section{*Correspondence:}

Dr. Sourabha S. Shetty,

E-mail: sourabhashetty4@gmail.com

Copyright: (c) the author(s), publisher and licensee Medip Academy. This is an open-access article distributed under the terms of the Creative Commons Attribution Non-Commercial License, which permits unrestricted non-commercial use, distribution, and reproduction in any medium, provided the original work is properly cited.

\begin{abstract}
Background: Postnatal care is the important portion of maternal health care as it helps to assess the health status of mother and newborn. It promotes to rectify the defect and to identify the progress of the baby that is essential to solve the health issues.

Methods: All 100 postnatal women were assessed regarding awareness of self and newborn care using structured questionnaire.

Results: In this study maximum number were in age group of 21-25 years (42\%). Majority of respondents were literate $(88 \%)$. Main source of information regarding postnatal and neonatal care is given by health care personnel (49\%). $77 \%$ cleaned the perineum after defecation and urination. 39\% of postnatal mothers practice postnatal exercise. 54\% were aware of spacing between two pregnancies. Majority of mothers agreed that colostrum is first breast milk and are aware on giving it to newborn (68\%). $78 \%$ are aware of exclusively breast feeding baby for 6 months. $79 \%$ of postnatal women were aware vaccines prevent diseases in baby. Postnatal mothers had good awareness about self and newborn care.

Conclusions: The first 48 hours after delivery is the time when the mother and baby are most vulnerable to morbidity and mortality associated with childbirth. Postnatal care is one of the most important maternal health care for not only prevention of impairment and disabilities, but also for reduction of maternal and neonatal mortality and morbidity.
\end{abstract}

Keywords: Exclusive breast feeding, Awareness of self and newborn care, Postnatal care

\section{INTRODUCTION}

Postnatal period begins after the third stage of labour and includes first six weeks after delivery. During this time women's reproductive organs gradually return to the normal size and shape. Postnatal period is a crucial period in woman's life as physiological changes occur. Women are in need of special care during pregnancy, at the time of labour as well as after delivery of child in order to have safe motherhood and healthy living. ${ }^{1}$ The postnatal period is a critical transitional time for a woman and her newborn physiologically, emotionally and socially. ${ }^{2}$ Postnatal care is one of the most important maternal health care for not only prevention of impairment and disabilities, but also for reduction of maternal mortality. Women should be advised of the signs and symptoms of potentially life-threatening conditions.

World Health Organization (WHO) suggests that health care should be provided at 6 hours, 6 days, 6 weeks and 6 months post-delivery in order to ensure women's physical and mental health and well-being. ${ }^{9}$ Low utilization of postnatal care has been related to women's lack of knowledge about its importance, their lack of perceived need, their low level of education, poverty, lack of access to health care facilities that provide postnatal care, lack 
of appointments or recommendations from health care providers to obtain postnatal care, poor attitudes of the health care providers or women's tendency to give priority to the health needs of their infants rather than their own care. Postnatal care includes systematic examination of mother and the newborn.

Postnatal care provision crosses acute and primary health care sectors, with the majority of care taking place in the women's home. Care is likely to include routine clinical examination and observation of the women and health baby, routine infants screening to detect potential disorders, support for infant feeding and ongoing provision of information and support. Postnatal care is usually concluded by a 6 to 8 -week postnatal examination, which marks the end of the women's maternity care. ${ }^{9}$

Every society and country have its own traditional belief and practice related to postnatal and newborn care. Some of the rituals and beliefs are beneficial to the mother and child. But some of them are more dangerous to the health aspects. It is an important role of health care providers to identify the harmful belief.

During the postnatal period a variety of interventions aid in healing process includes cleanliness, prevention of infection, exercise and nutritional diet. The healthcare providers should educate the mother about intervention which will help the mother to gain adequate knowledge and maintain positive health for herself and the baby. Health education is an integral part of maternal and child health care. ${ }^{1}$ The first 48 hours after delivery is the time when the mother and baby are most vulnerable to morbidity and mortality associated with childbirth. ${ }^{10}$

WHO has also recommended essential newborn care practices are crucial interventions; which includes clean cord care, thermal protection, early and exclusive breastfeeding, delay bathing, care for the low birth weight newborn and management of newborns. It is estimated that $75 \%$ of neonatal deaths could be avoided with simple, low-cost tools that already exist such as sterile blades to cut the umbilical cord, using clean dry clothes to wrap and keep babies warm and early initiation of breastfeeding. ${ }^{10}$

Inadequate, improper and inappropriate care in postnatal period may result in death as well as missed opportunity to promote healthy behavior that will be affecting the health of mother and newborn. Postnatal care is the important portion of maternal health care as it helps to assess the health status of mother and new-born. The importance of personal care include diet, perineal hygiene, postnatal exercises, breast feeding and the general newborn care. ${ }^{8}$ It promotes to rectify the defect and to identify the progress that is essential to solve the health issues. It also helps to provide necessary information and education to the mother regarding maternal and new-born care. Qualitative approaches suggest as a complement to quantitative assessments, in order to increase understanding about the patient perspective on care received. ${ }^{2}$

\section{METHODS}

This study was conducted in A.J. Institute of Medical Sciences, Mangalore under department of Obstetrics And Gynaecology. It is a Hospital based cross-sectional study. This study was conducted from January 2020 to March 2020. Women were included in study following delivery of a live baby in A.J. Institute of Medical Sciences during the study period who were willing to give consent to the study. Women who did not give consent were not included in the present study.

A structured questionnaire was given to 100 postnatal mothers who had given consent to take part in the study. The questionnaire was based regarding self and new-born care of the mothers which included questions on demographic details, postnatal diet of the mother, questionnaire on awareness on personal hygiene, postnatal check-up, postnatal exercises, family planning practices. It also includes questionnaire on awareness of postnatal mothers regarding new-born care such as breast-feeding practices, immunisation, thermoregulation and cord care of the new-born. The questionnaire was given to postnatal mothers who were in both English and Kannada and were asked to tick to the appropriate answer. Statistical analysis is done using chi square test and Fisher test. $\mathrm{P}$ value $<0.5$ was statistically significant.

\section{RESULTS}

The study included 100 participants. The sociodemographic characteristics of the participants are as depicted in (Table 1). Majority of the postnatal mothers were between age group of 21- 25 years (42\%). Total $88 \%$ of the respondents were literate. In this study $48 \%$ were primigravida and $52 \%$ were multigravida. Main source of information regarding postnatal and new-born care by health care personnel (49\%) (Table 1).

Regarding self-care, awareness of the postnatal mothers is as depicted in (Table 2). In present study, $77 \%$ cleaned the perineum after defection and urination. Among which only $53 \%$ were aware that perineum was to be cleaned from front to back, $81.5 \%$ of respondents took bath daily. Total $65 \%$ of the participants used cottons pads and $78.5 \%$ of participants changed their cotton pads/clothes frequently. The postpartum women in the present study were aware that perineal hygiene reduce the risk of infection and it is an important awareness to prevent infection. Also $56 \%$ of study participants drank about 3 litres of water every day and 52\% have increased the intake of vegetables/ fruits during post-natal period. Total $39 \%$ of postnatal mothers practice postnatal exercise and $30 \%$ perform leg exercise by rotating ankles, flexing and extending the legs. 
In this study $54 \%$ postnatal mothers were aware of spacing between two pregnancies. $57 \%$ preferred to use condom as a contraceptive measure. $54 \%$ of postnatal mothers were aware of postnatal and $43 \%$ were aware of danger signs in postnatal period (Table 2).

Table 1: Demographic details of study participants.

\begin{tabular}{|c|c|c|c|}
\hline Demographic Variables & & Number $(n=100)$ & Percentage (\%) \\
\hline \multirow{3}{*}{ Age (in years) } & $18-20$ & 40 & 20 \\
\hline & $21-25$ & 84 & 42 \\
\hline & $>26$ & 76 & 38 \\
\hline \multirow{4}{*}{ Educational status of mother } & Illiterate & 24 & 12 \\
\hline & Primary school & 76 & 38 \\
\hline & Higher Secondary & 43 & 21.5 \\
\hline & degree & 57 & 28.5 \\
\hline \multirow{2}{*}{ Occupational status of mother } & Employed & 52 & 26 \\
\hline & Unemployed & 148 & 74 \\
\hline \multirow{3}{*}{ Family income (monthly) } & Below Rs 5000/- & 24 & 12 \\
\hline & Rs.5000/- to Rs $10,000 /-$ & 108 & 54 \\
\hline & Rs.10,001/- and above & 68 & 34 \\
\hline \multirow{2}{*}{ Type of the family } & a)Nuclear & 93 & 46.5 \\
\hline & b) Joint & 107 & 53.5 \\
\hline \multirow{2}{*}{ Area of residence } & Urban & 77 & 38.5 \\
\hline & Rural & 123 & 61.5 \\
\hline \multirow{3}{*}{$\begin{array}{l}\text { Source of information regarding postnatal } \\
\text { care and neonatal care }\end{array}$} & Relatives and friends & 46 & 23 \\
\hline & Neighbours & 56 & 28 \\
\hline & Health personnel & 98 & 49 \\
\hline \multirow{2}{*}{ Obstetric score } & Primigravida & 96 & 48 \\
\hline & Multigravida & 104 & 52 \\
\hline
\end{tabular}

Table 2: Awareness of postnatal mothers regarding self care.

\begin{tabular}{|c|c|c|c|}
\hline \multicolumn{2}{|l|}{ Personal hygiene } & \multirow{2}{*}{$\begin{array}{l}\begin{array}{l}\text { Number } \\
(\mathrm{n}=\mathbf{1 0 0})\end{array} \\
154\end{array}$} & \multirow{2}{*}{$\begin{array}{l}\text { Percentage (\%) } \\
77\end{array}$} \\
\hline Do you clean your perineum each time after defecation and & Yes & & \\
\hline urination? & No & 46 & 23 \\
\hline \multirow{2}{*}{ Do you clean your perineum from front to back? } & Yes & 106 & 53 \\
\hline & No & 94 & 47 \\
\hline \multirow{2}{*}{ Do you take bath once in a day? } & Yes & 163 & 81.5 \\
\hline & No & 37 & 18.5 \\
\hline \multirow{2}{*}{ Do you use cotton pads? } & Yes & 130 & 65 \\
\hline & No & 70 & 35 \\
\hline \multirow{2}{*}{ Do u change pads/ clothes frequently? } & Yes & 157 & 78.5 \\
\hline & No & 43 & 21.5 \\
\hline Postnatal diet & & $\begin{array}{l}\text { Number } \\
(n=100)\end{array}$ & Percentage $(\%)$ \\
\hline \multirow{2}{*}{$\begin{array}{l}\text { Have you increased the intake of vegetables/ fruits during post } \\
\text { natal period? }\end{array}$} & Yes & 104 & 52 \\
\hline & No & 96 & 48 \\
\hline \multirow{2}{*}{$\begin{array}{l}\text { Do you consume adequate of water everyday (about } 3 \text { liters ) } \\
\text { ? }\end{array}$} & Yes & 112 & 56 \\
\hline & No & 88 & 44 \\
\hline \multicolumn{2}{|l|}{ Postnatal exercises } & $\begin{array}{l}\text { Number } \\
(\mathrm{n}=100)\end{array}$ & Percentage $(\%)$ \\
\hline \multirow{2}{*}{ Do you practice any postnatal exercises? } & Yes & 78 & 39 \\
\hline & No & 122 & 61 \\
\hline \multirow{2}{*}{$\begin{array}{l}\text { Do you perform leg exercises by rotating } \\
\text { ankles and flexing and extending the legs ? }\end{array}$} & Yes & 60 & 30 \\
\hline & No & 140 & 70 \\
\hline
\end{tabular}


Table 3: Awareness of postnatal mothers regarding self care.

\begin{tabular}{|llll|}
\hline Family Planning & Yes & \multicolumn{1}{c|}{$\begin{array}{l}\text { Number } \\
(\mathbf{n = 1 0 0})\end{array}$} & $\begin{array}{l}\text { Percentage } \\
(\%)\end{array}$ \\
\hline $\begin{array}{l}\text { Are you aware of spacing between two } \\
\text { pregnancies? }\end{array}$ & No & 108 & 54 \\
\hline \multirow{3}{*}{ Contraceptive measure prefer } & Condom & 92 & 46 \\
\cline { 2 - 4 } & OCPs & 114 & 57 \\
\cline { 2 - 4 } & IUD & 6 & 3 \\
\cline { 2 - 4 } Postnatal check-up & Sterilisation & 64 & 8 \\
\hline \multirow{2}{*}{ Are you aware of postnatal check-up? } & & $\begin{array}{l}\text { Number } \\
(\mathbf{n}=\mathbf{1 0 0})\end{array}$ & $\begin{array}{l}\text { Percentage } \\
(\mathbf{\%})\end{array}$ \\
\hline \multirow{2}{*}{ Are you aware of danger signs? } & Yes & 108 & 54 \\
\hline & No & 92 & 46 \\
\cline { 2 - 4 } & Yes & 86 & 43 \\
\hline
\end{tabular}

Table 4: Awareness of postnatal mothers on newborn care.

\begin{tabular}{|c|c|c|c|}
\hline \multicolumn{2}{|l|}{ Breast Feeding } & \multirow{2}{*}{$\begin{array}{l}\begin{array}{l}\text { Number } \\
(\mathbf{n}=100)\end{array} \\
144\end{array}$} & \multirow{2}{*}{$\begin{array}{l}\text { Percentage } \\
(\%) \\
72\end{array}$} \\
\hline Do you feed your baby by sitting position with supporting the & Yes & & \\
\hline babies head with elbow? & No & 56 & 8 \\
\hline \multirow{2}{*}{$\begin{array}{l}\text { Honey / water / formula feed should be given to baby before } \\
\text { starting breast feeding }\end{array}$} & Yes & 117 & 58.5 \\
\hline & No & 83 & 41.5 \\
\hline \multirow{2}{*}{ Colostrum should be given to baby } & Yes & 136 & 68 \\
\hline & No & 64 & 32 \\
\hline \multirow{2}{*}{ Exclusive breast feeding for 6 months } & Yes & 144 & 72 \\
\hline & No & 56 & 28 \\
\hline \multirow{2}{*}{ Do you burp your baby after the feed? } & Yes & 124 & 62 \\
\hline & No & 76 & 38 \\
\hline \multicolumn{2}{|l|}{ Immunisation } & $\begin{array}{l}\text { Number } \\
(n=100)\end{array}$ & $\begin{array}{l}\text { Percentage } \\
(\%)\end{array}$ \\
\hline \multirow{2}{*}{ Vaccines prevent diseases in your baby } & Yes & 158 & 79 \\
\hline & No & 42 & 21 \\
\hline \multirow{2}{*}{ Are you aware of National Immunisation Schedule? } & Yes & 123 & 61.5 \\
\hline & No & 77 & 38.5 \\
\hline \multicolumn{2}{|l|}{ Thermoregulation } & $\begin{array}{l}\text { Number } \\
(\mathrm{n}=100)\end{array}$ & $\begin{array}{l}\text { Percentage } \\
(\%)\end{array}$ \\
\hline \multirow{2}{*}{ Baby should be nursed in the same room as mother } & Yes & 182 & 91 \\
\hline & No & 18 & 9 \\
\hline \multirow{2}{*}{ Does skin to skin contact prevents heat loss in your baby? } & Yes & 114 & 57 \\
\hline & No & 86 & 43 \\
\hline \multirow{2}{*}{ Warm clothing prevents heat loss in your baby } & Yes & 186 & 93 \\
\hline & No & 14 & 7 \\
\hline \multirow{2}{*}{ First bath given to the baby after 24 hours? } & Yes & 121 & 60.5 \\
\hline & No & 79 & 39.5 \\
\hline \multicolumn{2}{|l|}{ Cord care } & $\begin{array}{l}\text { Number } \\
(\mathrm{n}=100)\end{array}$ & $\begin{array}{l}\text { Percentage } \\
(\%)\end{array}$ \\
\hline \multirow{2}{*}{$\begin{array}{l}\text { The cord should be left clean and dry without applying } \\
\text { substances }\end{array}$} & Yes & 138 & 69 \\
\hline & No & 62 & 31 \\
\hline \multirow{2}{*}{ A soiled umbilical stump should be cleaned with water } & Yes & 176 & 88 \\
\hline & No & 24 & 12 \\
\hline
\end{tabular}


In this study $78 \%$ are aware of exclusively breast-feeding baby 6 months. $58.5 \%$ were aware of avoiding honey/ water and formula feed before starting breast feeding. $72 \%$ of postnatal mothers feed their baby by sitting position with supporting the baby's head with elbow, $62 \%$ of women were aware to burp the baby after each feed (Table 3).

In the present study majority i.e. $79 \%$ were aware that vaccines prevent diseases and $61.5 \%$ of women were aware of national immunization schedule $57 \%$ of women were aware that skin to skin contact prevent heat loss in the baby and $69 \%$ of post-natal mothers were aware of cord care (Table 4).

\section{DISCUSSION}

Postnatal care is the important portion of maternal health care as it helps to assess the health status of mother and new-born. It promotes to rectify the defect and to identify the progress of the baby that is essential to solve the health issues. It also helps to provide necessary information and education to the mother regarding maternal and new-born care.

The traditional postpartum convalescent concepts impacted women's postpartum dietary and health behaviours greatly, especially those residing in rural area or being less educated. Higher education level was positively associated with not complying with traditional behaviour taboos. In this study majority of the participants are literate i.e. $88 \%$ and $53.5 \%$ were from joint family, with $38.5 \%$ from rural area, $48 \%$ primigravida participated in the study. Also 52\% increased the intake of fruits and vegetable, $56 \%$ drank about 3 litres of water every day. This was in contrast to a study done in Mexico where fruits and vegetables (62\%) and legumes (20\%) were the most avoided food groups.

In this study postnatal mothers had awareness of perineal hygiene, which was in accordance with the crosssectional study conducted in port Harcoun teaching hospital, Niger to evaluate knowledge and practice of perineal hygiene among postnatal mothers. Participants were selected by systematic random sampling. Data was collected by using structured questionnaire. The study reveals that $56.9 \%$ use sanitary pads for perineal hygiene, $90 \%$ had knowledge regarding application of pad from vulva to anus and cleansing of perineal area from front to back. $88 \%$ had knowledge and practice regarding cleaning of perineal area after emptying of bowel and bladder. The postpartum Women in the present study were aware of vulval and perineal hygiene. Careful hygiene to reduce the risk of infection seemed to be an important belief with respect to the vulval and perineal area. $^{15}$

In a study conducted by Chythra and Dhanya in Manipal, Karnataka showed that all postnatal mothers engaged in routine household work and very few (19\%) were performing exercises during the postpartum period, which was in accordance with this study, where $39 \%$ were practising postnatal exercises and $30 \%$ perform leg exercise by rotating ankles, flexing and extending the legs. ${ }^{14}$

In comparison to present study, a study conducted by Timilsina S and Rojana Dhakal R majority of respondents $186(94.90 \%)$ stated condom was most commonly used contraceptive measure. In this study $54 \%$ postnatal mothers were aware of spacing between two pregnancies. $57 \%$ preferred to use condom as a contraceptive measure and only $32 \%$ preferred sterilisation procedure, due to fear of operation and its side effects. ${ }^{15}$

In this study $54 \%$ of postnatal mothers were aware of postnatal checkup and $43 \%$ were aware of danger signs on postnatal period which was accordance to the study conducted by Zomba Central Hospital, Malawi, 67\% of participants know benefit of postnatal checkup.

Regarding new-born care in this study $72 \%$ are aware of exclusively breast-feeding baby up to 6 months. $58.5 \%$ were aware of avoiding honey/water and formula feed before starting breast feeding. $72 \%$ of postnatal mothers feed their baby by sitting position with supporting the baby head with elbow, $62 \%$ of women were aware to burp the baby after each feed. In a study conducted by Vijayalakshmi et al in Bangalore, majority $(88.5 \%)$ of the mothers breast fed their infants. While, $85.2 \%$ of the mothers were aware of EBF, merely $27 \%$ were exclusive breast feeders. Also, the prevalence of exclusive breastfeeding at six months is generally low in low resource countries and varies from $9 \%$ to $40 \% .^{13}$

In the present study majority i.e. $79 \%$ were aware that vaccines prevent diseases and $61.5 \%$ of women were aware of national immunization schedule. Total $57 \%$ of women were aware that skin to skin contact prevent heat loss in the baby and $69 \%$ of post-natal mothers were aware of cord care. This finding was supported by the descriptive cross sectional study which was done in Zomba Central Hospital, Malawi to assess the knowledge, views and practice of mother regarding postnatal care. Structured interview schedule was used to collect data. The study result shows that almost all the participants were knowledgeable about some aspect of postnatal care. Total $33.8 \%$ participants knew about vaccination and cord care. Total $27.8 \%$ of participants were not sure how the six week postnatal care promotes the health of mothers. ${ }^{1}$

\section{CONCLUSION}

In conclusion, the present study highlights the knowledge on postnatal care and newborn care among postnatal mothers. This study shows that the most knowledgeable area was perineal hygiene, danger sign of mother and newborn, breast feeding practices, immunization of newborn, thermoregulation and cord care. The least 
knowledgeable area was postnatal diet, postnatal exercise and family planning.

Female literacy should be improved and more intensive training should be given to community health workers in order to promote effective postnatal care. At the same time improving access to health service is also important factor by the government sectors. Low utilization of postnatal care has been related to women's lack of knowledge about its importance, their lack of perceived need, their low level of education, poverty, lack of access to health care facilities that provide postnatal care, lack of recommendations from health care providers to obtain postnatal care, poor attitudes of the health care providers or women's tendency to give priority to the health needs of their infants rather than their own care. Hence postnatal care includes systematic examination of mother and the newborn. The present study concludes that the mothers have an average awareness regarding postnatal and newborn care. Hence awareness programs are required to improve knowledge on the different aspects of postnatal care.

\section{ACKNOWLEDGMENTS}

Authors would like to thank the support and cooperation of all the patients involved in the study.

Funding: No funding sources

Conflict of interest: None declared

Ethical approval: The study was approved by the Institutional Ethics Committee

\section{REFERENCES}

1. Missiriya S. Knowledge and practice of postnatal mothers regarding personal hygiene and newborn care. Inter J Pharma Sci. 2016;40(1):89-93.

2. Tesfahun F, Worku W, Mazengiya F, Kifle M. Knowledge, perception and utilization of postnatal care of mothers in Gondar Zuria District, Ethiopia: a cross-sectional study. Mater Chi Heal J. 2014;18(10):2341-51.

3. MacArthur C, Winter HR, Bick DE, Knowles H, Lilford R, Henderson C, et al. Effects of redesigned community postnatal care on women's health 4 months after birth: a cluster randomized controlled trial. Lancet. 2002;359(9304):378-85.

4. CDC - NCHS -National Center for Health Statistics, 2015. Available at: https://www.cdc.gov/nchs/. Accessed Feb 192016.
5. Shrestha T, Bhattarai SG, Silwal K. Knowledge and practice of postnatal mother in newborn care. J Nepal Med Associa. 2013;52(190):372-7.

6. Darmstadt GL, Bhutta ZA, Cousens S, Adam T, Walker N, de Bernis L. Lancet Neonatal Survival Steering Team. Evidence based, cost-effective interventions: how many new born babies can we save? Lancet. 2005;365(9463): 977-88.

7. Mundia GM. A study on the knowledge and attitudes of the women at Kasama Urban clinic about postnatal care. University of Zambia, 2012. Available at: http://hdl.handle.net/123456789/1622.

8. Colemore J. Mothers use of knowledge in Perineal hygiene, 2009. Available at: http://www.washingtonpost.com.

9. Memchoubi K, Kudale A, Lilileima L, Koshy L, Londhe S. A study to assess the knowledge of postnatal mothers regarding self-care after childbirth in Bharati hospital and research centre, Pune. IJAR. 2017;3(6):1115-7.

10. Semanew Y, Etaye M, Tizazu A, Abebaw D, Gebremedhin T. Newborn care practices and its determinants among postnatal mothers in Dessie Referral Hospital, Northeast Ethiopia. BMC research notes. 2019;12(1):96.

11. Liu N, Mao L, Sun X, Liu L, Chen B, Ding Q. Postpartum practices of puerperal women and their influencing factors in three regions of Hubei, China. BMC Pub Heal. 2006;6:274.

12. Raven JH, Chen Q, Tolhurst RJ, Garner P. Traditional beliefs and practices in the postpartum period in Fujian Province, China: a qualitative study. BMC Preg Child. 2007;7(1):8.

13. Vijayalakshmi P, Susheela T, Mythili D. Knowledge, attitudes, and breast feeding practices of postnatal mothers: A cross sectional survey. International J Heal Sci. 2015;9(4):364.

14. Rao CR, Dhanya SM, Ashok K, Niroop SB. Assesment of cultural beliefs and practices during the postnatal period in a costal town of South IndiaAmixed method research study. Global J Med Pub Heal. 2014;3(5):1-8.

15. Timilsina S, Dhakal R. Knowledge on postnatal care among postnatal mothers. Saudi J Med Pharm Pci. 2015;1:87-92.

Cite this article as: Ganiga P, Shetty SS. A prospective study on awareness of postnatal mothers regarding self and newborn care in a tertiary care centre in Mangalore, Karnataka. Int J Reprod Contracept Obstet Gynecol 2021;10:239-44. 